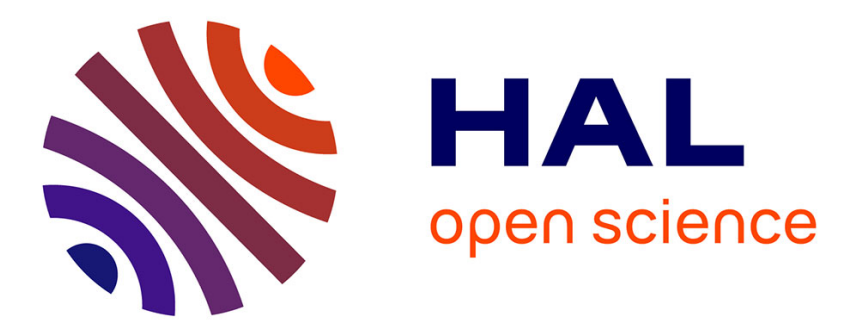

\title{
Improving surgical safety globally: pulse oximetry and the WHO Guidelines for Safe Surgery
}

Isabeau Alexandra Walker, Mark Newton, Adrian T Bosenberg

\section{To cite this version:}

Isabeau Alexandra Walker, Mark Newton, Adrian T Bosenberg. Improving surgical safety globally: pulse oximetry and the WHO Guidelines for Safe Surgery. Pediatric Anesthesia, 2011, 21 (7), pp.825. 10.1111/j.1460-9592.2010.03500.x . hal-00613822

\section{HAL Id: hal-00613822 \\ https://hal.science/hal-00613822}

Submitted on 6 Aug 2011

HAL is a multi-disciplinary open access archive for the deposit and dissemination of scientific research documents, whether they are published or not. The documents may come from teaching and research institutions in France or abroad, or from public or private research centers.
L'archive ouverte pluridisciplinaire HAL, est destinée au dépôt et à la diffusion de documents scientifiques de niveau recherche, publiés ou non, émanant des établissements d'enseignement et de recherche français ou étrangers, des laboratoires publics ou privés. 


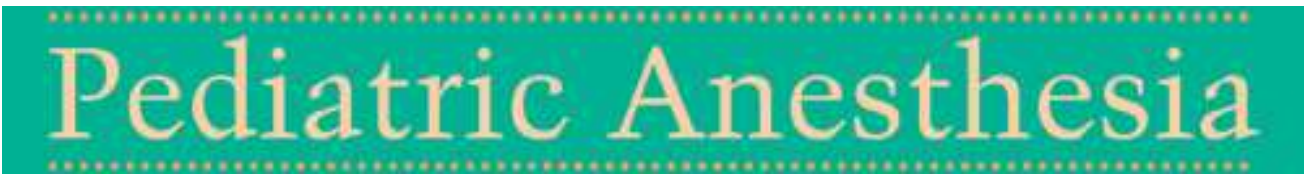

\section{Improving surgical safety globally: pulse oximetry and the WHO Guidelines for Safe Surgery}

\begin{tabular}{|c|c|}
\hline Journal: & Pediatric Anesthesia \\
\hline Manuscript ID: & PAN-2010-0472.R1 \\
\hline Wiley - Manuscript type: & Review (commissioned) \\
\hline $\begin{array}{l}\text { Date Submitted by the } \\
\text { Author: }\end{array}$ & 07-Nov-2010 \\
\hline Complete List of Authors: & $\begin{array}{l}\text { Walker, Isabeau; Great Ormond Street Hospital NHS Trust, } \\
\text { Anaesthesia } \\
\text { Newton, Mark; Vanderbilt, Anesthesiology } \\
\text { Bosenberg, Adrian; Seattle Children's Hospital, Anesthesiology }\end{array}$ \\
\hline Key Words: & $\begin{array}{l}\text { child < Airway, Developing World, quality improvement }< \\
\text { Outcomes, General anesthesia }\end{array}$ \\
\hline
\end{tabular}


Improving surgical safety globally: pulse oximetry and the WHO Guidelines

\section{for Safe Surgery}

Walker IA, Newton M, Bosenberg AT.

Dr I A. Walker (corresponding author)

Consultant Anaesthetist

Great Ormond Street Hospital NHS Trust

London WC1N 3JH

UK

isabeauwalker@mac.com

Dr M.W Newton

Associate Professor of Clinical Anesthesiology,

Vanderbilt University,

2200 Children's Way Suite 3115,

Nashville, TN 37232-9070,

USA.

mark.w.newton@vanderbilt.edu 
Professor A.T. Bosenberg

Professor Anesthesiology,

University Washington

Director Regional Anesthesia

Seattle Children's Hospital

4800 Sandpoint way NE

Seattle WA 98105

USA

adrian.bosenberg@seattlechildrens.org

Word Count: 2,344 


\begin{abstract}
Summary
Access to safe surgery should be considered as part of the basic human right for health, but unfortunately this ideal is far from being reached in many lowincome countries. Pulse oximetry is recommended as a minimum standard of monitoring by all anesthesia organizations that have set standards, yet around 78,000 operating theaters worldwide lack this essential monitor. The WHO Safe Surgery Saves Lives Program has identified evidence-based guidelines for safe surgery that are applicable in any setting, and the Global Pulse Oximetry Program will help to improve access to pulse oximetry in countries where it is not available. However, these initiatives are just a start; capacity, infrastructure, trained healthcare providers and access to essential drugs and equipment for anesthesia and surgery need to become a public health priority in many lowincome countries.
\end{abstract}


Anesthesia safety has improved considerably in recent years in the wake of advances in technology, the development of new drugs, improvements in training, adoption of standards, guidelines and incident monitoring. More recently, through the use of simulation and with a better understanding of human factors, further improvements can be expected (1). In the USA, anesthesia-related mortality for surgical in-patients was estimated to be 1:2700 in 1948-52, and is currently estimated to be 1: 122,000 - 1: $200000(2,3)$. However, these advances in anesthesia safety have not been realized globally. A recent paper describing pediatric anesthesia in Benin documents a perioperative cardiac arrest rate of 1:64 anesthetics (62\% mortality) (4). Reports from sub-Saharan Africa describe anesthesia mortality ranging from 1:133 to 1:1900 for adult and pediatric practice, similar to that seen in high-income countries more than fifty years ago (5). How can access to safe anesthesia and surgery become a reality for all populations in the $21^{\text {st }}$ Century?

One of the primary challenges to improving outcomes from anesthesia and surgery is access to timely surgical care delivered by adequately trained and resourced healthcare providers. This should be recognized as part of the basic human right to health, but this ideal is far from being realized $(6,7)$. Of the estimated 234 million surgical procedures that are performed each year, $74 \%$ procedures occur in high- and middle- healthcare expenditure countries (representing $30 \%$ of the world's population), $23 \%$ in low-healthcare expenditure countries (35\% of the world's population) and $3.5 \%$ occur in poor- healthcare expenditure countries (35\% of the 
world's population) (8). Africa suffers disproportionately, with $25 \%$ of the global burden of disease and only $2 \%$ of the global health workforce (9).

A recent survey describes the situation for pediatric surgery in southwest Uganda (10). The pediatric surgical rate was $3 \%$ of that seen in England, and most surgery related to emergency procedures for burns, trauma and infectious complications. Presentation for elective surgery for congenital abnormalities was considerably delayed, and many emergency patients were referred from rural hospitals to regional hospitals for surgery due to lack of essential resources. Such patients are likely to present a significant challenge to both surgeon and anesthesia provider. The surgical workforce was 5\% of that in England (no specialist pediatric surgeons); the specialist anesthesiology workforce 1\% of that in England, and 20\% of anesthesia providers had no formal training at all ('trained on job'). Essential supplies such as oxygen, basic airway equipment, electricity and running water were not always available and none of the hospitals in the region reached WHO standards for essential surgery. Although Uganda is used as an example, the shortfall in infrastructure, supplies, workforce and volume of surgical activity is typical of many low- and middle-income countries $(11,12,13)$. Anesthesia and surgical providers need the tools of their trade, and poor anesthesia outcomes described in these circumstances should not surprise us (4). Placing complex patients in the hands of inadequately trained and poorly resourced anesthesia providers undergoing surgery with inexperienced clinicians would likely be associated with high mortality anywhere. So how do we improve the situation?

Limited health expenditure is the greatest barrier to improving the outcomes from 
healthcare. In Uganda, for example, the per capita government expenditure on health is $\$ 20$ (compared to $\$ 2446$ in the UK), and many families are required to make out of pocket contributions for their own healthcare. A recent survey of district hospitals in Africa identified a per capita expenditure on surgery of only $\$ 0.05-\$ 0.14$, most of this relating to obstetric care (14). International donor organizations tend to focus public health policies on infectious diseases, malaria and HIV, but a shift of emphasis towards surgical care is long overdue.

Surgical diseases are thought to account for $11 \%$ of the global burden of disease, whilst diseases such as HIV, malaria and tuberculosis account for only $1.3 \%$ of the global burden of disease (6). Injuries are responsible for more deaths of African children over five than HIV, malaria and tuberculosis combined. Essential surgical care can be achieved with similar cost effectiveness to childhood vaccination programs. In addition improving the facilities for surgical care may have the added benefit of strengthening health systems for the delivery of primary care. These factors need to be addressed as a priority $(7,15)$.

Although resources are the greatest barrier to safe care, there is much that can be done to make sure that existing resources are used efficiently, in particular by ensuring that care is planned and delivered by individuals who are working well as a team. The WHO Patient Safety initiative was established in 2004, led by Sir Liam Donaldson, then Chief Medical Officer in England. The second WHO Global Patient Safety Challenge "Safe Surgery Saves Lives" (SSSL) was launched in 2008 in acknowledgement of the fact that the global volume of surgery is significant and that 
adverse events from surgery constitute a significant public health concern. Major complications feature in 3\%-22\% of inpatient surgical procedures, with a death rate of 0.4\%-10\%, depending on the setting. Worldwide, an estimated 7 million patients suffer postoperative surgical complications annually, and 1 million patients die (16).

Evidence-based interventions to improve surgical safety were considered by the SSSL team led by surgeon and public health physician Atul Gawande. An international consortium including representatives from surgery, anesthesia, nursing, infection control and quality improvement convened to write evidence-based guidelines and identify a core set of safety standards that could be applied in all countries and in all settings (16). The most common complications during and after surgery that were considered included unanticipated hemorrhage, surgical site infections, anesthesia complications or incorrect site surgery. Many complications were considered preventable by good communication and teamwork. The Surgical Safety Checklist was designed to facilitate implementation of the WHO Guidelines for Safe Surgery, and focuses on critical points during the patient's journey through theatre, prior to induction (Sign in), prior to incision (Time out) and at the end of surgery (Sign out). The 19-point checklist includes key elements that contribute to surgical safety such as checking cross-match of blood for surgery, anesthesia equipment, the appropriate administration of antibiotics, whilst facilitating communication within the surgical team, one of the essential 'human factors' elements so often neglected in surgical care. 
The SSSL team investigated the impact of the Checklist in eight hospitals worldwide, four in high-income settings (USA, Canada, England, and New Zealand) and four in middle- and low-income settings (India, Jordan, Philippines and Tanzania (17). Data were collected prospectively from consecutively enrolled patients, 3733 before and 3955 after the introduction of the checklist. The overall mortality rate was reduced from $1.5 \%$ to $0.8 \%(\mathrm{p}=0.003)$ and in-patient complications from $11.0 \%$ to $7 \%$ $(\mathrm{p}<0.001)$. Similar reductions in morbidity and mortality were noted after urgent surgery (18). The checklist was launched in June 2008, and since then, more than 25 countries have introduced the checklist on a national scale. Local modification of the checklist to suit pediatric practice is encouraged and specific guidance is available on the Safe Surgery website http://www.safesurg.org (19).

Further evaluation of the impact of the checklist from national studies is awaited, but one of the principle effects appears to be improved communication and team working, as predicted from the earlier pilot work $(20,21)$. Improved teamwork with team training has recently been shown to have a striking effect on surgical mortality (22). Improved teamwork may be of particular relevance in low-income countries where professional hierarchies remain significant. The surgeon may be the only qualified doctor on site, and on occasion, non-medical anesthetists may feel cajoled into providing anesthesia when they do not feel adequately trained or resourced to do so (23). Improved teamwork and routine use of the checklist may raise the professional standing of surgical nursing, and support the use standard safety checks, for example patient identification bands, surgical marking and swab, needle and instrument counts. It is essential that surgeons and anesthesiologists support the principles of the checklist to overcome the practical challenges to its introduction (24). 
One of the checks required during the Sign in phase of the checklist is that a functioning pulse oximeter is on the patient prior to anesthesia. This item stands out as the single piece of equipment mandated by the WHO Checklist. Why is it there? During the development of the checklist, anesthesiologists from the expert group expressed the view that without universal pulse oximetry, the dramatic improvements in patient safety that followed the introduction of pulse oximetry into high-income countries in the mid-1980's would not be achieved in low-and middle-income counties, even with the use of the checklist (25). Although it could be argued that other monitoring modalities such as capnography are just as important, the expert group took the view that given the simplicity and reliability of the technology, pulse oximetry should be made available anywhere where general anesthesia or sedation is administered and should be a greater priority than all other anesthesia monitors. There are 58 countries that have established national standards of anesthesia monitoring, and all include the use of oximetry (26). Pulse oximetry has been included as a minimum level of monitoring for anesthesia in all settings internationally (27). However, recent data suggests that around 78,000 operating theatres worldwide are not equipped with pulse oximeters, thus affecting surgical safety for millions of patients in middle- and low- income countries (26).

Following the publication of the Surgical Checklist, the WHO recognized the need to start a process to ensure the availability of pulse oximeters everywhere in the world where surgery is performed. This initiative is known as the Global Pulse Oximetry Project (25). The current work has been informed by a project undertaken by the 
World Federation of Societies of Anaesthesiologists (WFSA) and Association of Anesthetists of Great Britain and Ireland (AAGBI) with an industry collaborator GE Healthcare, where 80 oximeters were introduced into different hospitals in Uganda, Philippines, India and Vietnam (28). This quality improvement project identified enthusiastic take up of the monitoring and training by anesthesia providers, many of whom had never used a pulse oximeter. There was evidence of learning and change of practice that was sustained over a period of time.

Education about both the WHO Checklist and the use of pulse oximetry is an important component of the Global Pulse Oximetry Project and a pilot evaluation of the checklist with pulse oximetry is planned. A procurement exercise has been followed by the WFSA to select a high quality, robust, low cost pulse oximeter meeting specifications for austere environments. Together with partners from the WHO, Harvard School of Public Health, AAGBI and Smile Train, the WFSA will use donor funds to start shipment of pulse oximeters to areas of need identified in lowand middle-income countries in early 2011 (contact GPOP@ anaesthesiolgists.org for further information).

Although the Global Pulse Oximetry Project and the WHO Checklist are major steps on the road to improve anesthesia and surgical care in middle- and lowincome countries, there are further questions that should be addressed. For instance, 'task shifting' is required as a pragmatic response to the shortage of healthcare workers. The optimal duration and method of training is unknown, and outcomes from training programs should be addressed. It would be helpful 
to develop accredited regional training programs, similar to that achieved by the Pan African College of Surgeons for East, Central, and Southern Africa, and the role of international partnerships should be investigated. An international standard for anesthesia machines suited to low-income countries is currently under development, and the design of equipment specifically suited to these environments is required (and could offer manufacturers new market opportunities). Anesthesia techniques suited to high-income countries may not be appropriate in all settings, and outcomes using different techniques should be investigated. For instance, ketamine-based anesthesia without intubation may offer improved outcomes in some poorly resourced settings (10).

There are also some major hurdles that must be addressed to improve the very high anesthesia mortality rates reported. Positive incentives are required to encourage trained providers to stay in-country, for instance development of postgraduate training programs, access to housing, salaries, and continuous professional development programs. International partnerships may be helpful in this context. Quality improvement initiatives can be successful in resourcepoor settings, but they require attention to basic infrastructure if improvements are to be maintained (29). Fewer than $30 \%$ of countries have a national blood transfusion service, and lack of blood for emergency surgery is a frequent problem (30). Essentials such as water, electricity, oxygen and basic airway equipment are often not available and emergency surgery may be delayed when patients have to buy antibiotics, sutures or surgical gloves $(11,31)$. 
Political buy in to the standards described by the WHO Guidelines for Safe Surgery at local, regional, national and international level is vital so that these critical limitations in surgical resources can be addressed. The public health challenges in providing safe surgical services are considerable, but essential surgical care has been neglected for too long. Widespread adoption of the WHO Surgical Safety Checklist and pulse oximetry should go a long way to improving surgical safety, but this is only the start of the journey.

\section{References}

1. Gaba D. Anaesthesiology as a model for patient safety in healthcare. BMJ 2000: 320: 785-7

2. Beecher HK, Todd DP. A study of the deaths associated with anesthesia and surgery: based on a study of 599, 548 anesthesias in ten institutions 1948-1952, inclusive. Ann Surg 1954; 140: 2-35

3. Li G, Warner M, Lang BH et al. Epidemiology of anesthesia-related mortality in the United States, 1999-2005 Anesthesiol 2009; 110:759-65.

4. Zoumenou E, Gbenou S, Assouto P et al. Pediatric anesthesia in developing countries: experience in the two main university hospitals of Benin in West Africa. Pediatr Anesth 2010; 20: 741-7.

5. Walker IA, Wilson IH. Anaesthesia in developing countries - a risk for patients. Lancet 2008; 371: 968-9 
6. Ozgediz D, Robert R. The “Other" Neglected Diseases in Global Public Health: Surgical Conditions in Sub-Saharan Africa. PLoS Med 2008; 5: e121

7. PLoS Editors. A crucial role for surgery in reaching the UN Millennium Development Goals PLoS Med 2008; 5: e182

8. Weiser TG, Regenbogen SE, Thompson KD et al. An estimation of the global volume of surgery: a modelling strategy based on available data. Lancet 2008; 38: 139-44

9. World Health Organization. World health report 2006: Working together for health. http://www.who.int/whr/2006/en/. (Accessed 3 $3^{\text {rd }}$ October 2010)

10. Walker IA, Obua AD, Mouton F et al. Paediatric surgery and anaesthesia in south-western Uganda: a cross-sectional survey. WHO Bulletin Published online $7^{\text {th }}$ June 2010 BLT.10.076703 http://www.who.int/bulletin/online_first/en/index.html (accessed 3rd October 2010)

11. Kushner AL, Cherian MN, Noel L. Addressing the Millennium Development Goals From a Surgical Perspective. Essential Surgery and Anesthesia in 8 Low- and Middle-Income Countries. Arch Surg. 2010; 145: 154-160

12. Dubowitz G, Detlefs S, McQueen KA. Global Anesthesia Workforce Crisis: A Preliminary Survey Revealing Shortages Contributing to Undesirable Outcomes and Unsafe Practices. World J Surg 2010; 34: 438-444 
13. Hodges SC, Walker IA, Bosenberg AT. Paediatric anaesthesia in developing countries. Anaesthesia 2007; 62: 26-31.

14. Kruk ME, Wladis A, Mbembati N. Human Resource and Funding Constraints for Essential Surgery in District Hospitals in Africa: A Retrospective Cross-Sectional Survey. PLoS Med 2010; 7: e1000242

15. Luboga S, Macfarlane DB, von Schreeb J et al. Increasing Access to Surgical Services in Sub-Saharan Africa: Priorities for National and International Agencies Recommended by the Bellagio Essential Surgery Group. PLoS 2009; 6: e1000200

16. World Health Organization. Guidelines for Safe Surgery: 2009: Safe Surgery Saves Lives. WHO Geneva 2009

17. Haynes AB, Weiser TG, Berry WR et al. A Surgical Safety Checklist to Reduce Morbidity and Mortality in a Global Population. NEJM 2009; 360: 491-9.

18. Weiser TG, Haynes AB, Dziekan G et al. Effect of a 19-item surgical safety checklist during urgent operations in a global patient population Ann Surg 2010; 251: 976-80

19. Safesurg.org. A website for information on how to reduce surgical deaths in surgical care globally. http://www.safesurg.org (accessed $3^{\text {rd }}$ October 2010) 
20. Sewell M, Adebibe M, Jayakumar P et al. Use of the WHO surgical safety checklist in trauma and orthopaedic patients Int Orthop 2010 Aug 21. (Epub ahead of print)

21. Lingard L, Regehr G, Oser B et al. Evaluation of a preoperative checklist and team briefing among surgeons, nurses, and anesthesiologists to reduce failures in communication. Arch Surg 2008; 143: 12-17.

22. Neily J, Mills PD, Young-Xu Y et al. Association between implementation of a medical team training program and surgical mortality. JAMA 2010; 304: 1693-1700

23. Dobson M. Training the trainers. Anaesthesia 2007; 62 (Suppl. 1): 96-102

24. Vats A, Vincent CA, Nagpal K. Practical challenges of introducing WHO surgical checklist: UK pilot experience BMJ 2010; 340: b5433

25. Merry AF, Eichhorn JH, Wilson IH. Extending the WHO 'Safe Surgery Saves Lives' project through Global Oximetry Anaesthesia 2009; 64:1045-8.

26. Funk LM, Weiser TG, Berry WR. Global operating theatre distribution and pulse oximetry supply: an estimation from reported data Lancet 2010; 376: $1055-6$

27. Merry AF, Cooper JB, Soyannwo 0 et al. International Standards for a Safe Practice of Anesthesia 2010. Can J Anaesth. 2010 Sep 21. [Epub ahead of print]

28. Walker IA, Merry AF, Wilson IH et al. Global oximetry: an international anaesthesia quality improvement project. Anaesthesia. 2009; 64:1051-60. 
29. Kotagal M, Lee P, Habiyakare C et al. Improving quality in resource poor settings: observational study from rural Rwanda BMJ 2009; 339: b3488

30. Bosenberg AT. Pediatric anesthesia in developing countries. Current Opinion in Anaesthesiology 2007; 20: 204-10.)

31. Hodges SC, Mijumbi C, Okello M et al. Anaesthesia services in developing countries: defining the problems. Anaesthesia 2007; 62: 4-11 